\title{
The Elderly Education System in the Context of Digital Transformation Construction and Value Pursuit
}

\author{
Xiao Yin \\ Zhejiang Open University, Hangzhou, China \\ Email: 357139169@qq.com
}

How to cite this paper: Yin, X. (2022) The Elderly Education System in the Context of Digital Transformation Construction and Value Pursuit. Open Access Library Journal, 9: e8375.

https://doi.org/10.4236/oalib.1108375

Received: January 14, 2022

Accepted: February 5, 2022

Published: February 8, 2022

Copyright $\odot 2022$ by author(s) and Open Access Library Inc.

This work is licensed under the Creative Commons Attribution International License (CC BY 4.0).

http://creativecommons.org/licenses/by/4.0/

\section{(c) (i) Open Access}

\begin{abstract}
Constructing an education system for the elderly under the background of digital transformation is the general trend and inevitable choice for the development of elderly education. Development and other aspects are of great significance. Based on China's basic national conditions and existing research results, this paper summarizes the main problems existing in the construction of the elderly education system and the pursuit of value, and puts forward specific suggestions to promote the healthy development of China's elderly education system and realize the sharing of elderly education resources.
\end{abstract}

\section{Subject Areas}

Elderly Education

\section{Keywords}

Digital Transformation, Senior Education, System Construction,

Value Pursuit

\section{Research Background}

Population aging is the basic national condition of China in the 21st century. It is predicted that by 2050 , China's elderly population will reach a peak of 487 million, accounting for one third of the total population. The problem of population aging has become one of the major social development challenges facing China. According to statistics, by 2020, the number of people aged 60 and above in the country will be 264.02 million, accounting for $18.70 \%$ of the total population; among them, the number of people aged 65 and above will be 190.64 million, accounting for $13.50 \%$. Compared with 2010 ten years ago, the proportion 
of the population aged 60 and above increased by 5.44 percentage points. In terms of provinces, there are 16 provinces with more than 5 million people aged 65 and above, of which 6 provinces have more than 10 million elderly people. According to the relevant standards of the United Nations, if the proportion of the population aged 65 and above exceeds 7\%, it will enter an aging society, and if it reaches $14 \%$, it can be called a deeply aging society. From the perspective of international standards, China's aging level is above the middle, and the process of population aging is also accelerating. The characteristics of "getting old before getting rich" are becoming more and more obvious and deepening, posing a serious challenge to China's economic and social development.

With the increasingly severe aging trend in China and the gradual improvement of people's quality of life, the problem of old-age care is no longer limited to solving the material and spiritual demands of the elderly, but also an important social issue related to whether the Chinese dream of great rejuvenation can be successfully realized. As a generally recognized important carrier and support for cultural elderly care, elderly education under the digital background is an important part of China's education and aging cause. The development of digital elderly education is an important part of modernizing education, actively responding to population aging, and building a learning society. It is an inevitable requirement to improve the quality of life of the elderly, meet the diverse learning needs of the elderly and promote social harmony. It is the central link and important starting point of the elderly education work. Actively building a senior education system and value pursuit under the background of digital transformation is the central task of China's senior education at present and in the future, and it has increasingly become an urgent problem that needs to be solved in the process of leading the development of China's senior education and the development of the cause of the elderly.

\section{Literature Review}

\subsection{Theoretical Basis}

The research on the construction and value pursuit of the elderly education system under the background of digital transformation mainly has the following three theoretical basis.

\subsubsection{Theory of Public Resource Allocation}

The theory argues that public services and infrastructure should be equitably allocated. As one of the important contents of public services, education administrative departments should establish and improve long-term mechanisms to ensure the balanced allocation of educational resources such as school-running funds, school-running conditions, teachers and salaries, and establish an evaluation and supervision mechanism for resource allocation. Due to the differences in politics, economy and political achievements, there are imbalances in educational resources for the elderly among regions, between urban and rural areas and between schools. The construction of the elderly education system should 
pay attention to the allocation of resources, so that the different main bodies of the elderly education can achieve the overall optimal allocation of resources, and promote the healthy and sustainable development of the elderly education.

\subsubsection{The Theory of Lifelong Education}

This theory holds that lifelong education is the sum of various educational contents and forms of education for different age groups, including all educational stages and formal and non-formal forms of education, to meet the diverse learning needs of each member at different stages of life, Promote the all-round development of members of society and the harmonious development of society. The previous education system generally lacked education specifically for the elderly. The theory of lifelong education clearly states that the elderly should enjoy the same right to education as other groups of different ages. The establishment of an education system for the elderly will further enrich and improve China's education system.

\subsubsection{Learning Social Theory}

This theory holds that a learning society was first defined by American educator Hutchins, and UNESCO believes that in a learning society, education is no longer mandatory, but a conscious responsibility of citizens to society, which is the future The ideal realm of educational development requires all sectors of society to actively undertake educational responsibilities and participate in this work together. At present, the elderly need to accept new things, constantly improve their quality, and learn modern science and technology in order to keep up with the pace of the times. Everyone should maintain a life-long learning state and pursue self-realization. This is the active lifestyle of most elderly people, and it is also an inherent requirement of the construction of a learning society [1].

\subsection{Research Status}

\subsubsection{Current Status of Foreign Research}

At present, foreign scholars' research in this field mainly starts from two levels. The first is to protect the right to education. In terms of guaranteeing the right of the elderly to participate in education, it is advocated that the right to education of the elderly should be guaranteed in the form of legislation, and special attention should be paid to the protection of the right to education of the elderly and vulnerable groups. In foreign practice, such as the United States and Germany, the elderly's financial security and educational rights are guaranteed from the height of legislation, and corresponding management agencies are established to implement them. Through legislation and other means, Japan and the United Kingdom have clarified the development direction of education for the elderly, and clearly proposed to attach importance to the professional development education of the elderly, and reduce or exempt elderly education funding subsidies and tuition burdens. The second is from the perspective of the supply model of 
the elderly. Foreign senior education has formed a variety of supply models. Scholars' research shows that foreign elderly education supply models mainly include six practical supply models, including community-based, school-based, remote network-based, self-help group-based, tourism-based, and library-based models. Among them, self-service elderly education is a bottom-up form of running a school. The main funds are membership fees and social donations, and students are encouraged to participate in management independently. The United Kingdom is the most typical; community-based elderly education relies on the community to carry out elderly education. In addition to government funding, there are also diversified sources, the most typical example of which is the United States; government-led education for the elderly is led by the government to set up universities for the elderly, bear part of the funds and incorporate them into the financial budget. The government plays an important role in the development of education for the elderly, with France being the most important. It is a typical example of government investment in elderly education, which provides a good reference for the development of elderly education in China [2].

\subsubsection{Domestic Research Status}

In recent years, domestic scholars' research in this field has mainly been carried out from the perspectives of increasing supply to promote the fairness of education for the elderly and guaranteeing the rights of the elderly to participate in education. First, the incremental supply promotes the fairness of elderly education. In view of the current situation of insufficient supply of senior education in China, some scholars have proposed reforming the management system, promoting the participation of multiple subjects, and expanding the supply of senior education, so as to further expand the coverage of senior education and promote the balanced development of senior education; some scholars have proposed supply-side reform of senior education, strengthen the supply guarantee mechanism and other measures to increase supply. The second is the protection of educational rights. China's elderly education began after the abolition of the tenure system for cadres in 1982, and the elderly education was positioned as "leisure and entertainment" education. For a long period of time, the supply of elderly education was mainly for retired cadres. Some scholars have discussed strengthening the protection of the rights and interests of the elderly in education from the aspects of promoting lifelong education legislation and lifelong education theory. To sum up, scholars at home and abroad have carried out many valuable researches on the supply of elderly education from different perspectives, but they have not paid certain attention to the quality and characteristics of the supply of elderly education. In the "Thirteenth Five-Year Plan for the Development of National Education" issued in early 2017, it is clearly required to "promote the gradual incorporation of elderly education institutions into the local public service system, improve the learning service system for the elderly, run universities for the elderly well, and effectively expand the supply of 
elderly education resources." Including the provision of public services for elderly education into an important part of China's public service system, and carrying out such research has great theoretical and practical significance [3].

\section{Development Status and Existing Problems}

\subsection{There Is a Problem of Uneven Development}

In recent years, various types of senior education institutions in China have developed rapidly, but the imbalance in the construction of the senior education system and the pursuit of value under the background of digital transformation has become increasingly prominent. In general, with the widespread implementation of digitalization and other modern teaching and publicity methods, the enrollment of senior education schools above the county and city level is relatively hot, while the elderly education institutions below the county and city level are often insufficient due to the lack of corresponding digital teaching resources and publicity methods. In particular, the development of grass-roots elderly education institutions such as streets and communities is relatively lagging behind, which objectively reflects the unbalanced development of the internal components of the elderly education system. According to the analysis of relevant data on the number of elderly education institutions in some provinces and cities in China and other relevant data released by relevant institutions, it can be seen that the economic conditions in East China and other regions are relatively good and the digital technology is fully used. The most, especially in Shanghai, with the vigorous promotion of various parties and the vigorous popularization of digital technology, major breakthroughs have been made in the establishment of elderly education institutions below the municipal level, a four-level elderly education network has basically been formed, and an initial construction of elderly universities at all levels has been established. The backbone, distance network education as the carrier and community education institutions as the support for the elderly education system. Although there are a large number of national demonstration universities for the elderly in the central and southern regions, the scale and number of grass-roots community elderly schools need to be further expanded. However, the number of grassroots senior colleges and national model senior colleges in the northwest region, where digital construction is relatively lagging behind, is significantly lower. It can be seen that there is a big gap in the construction of the elderly education system in various regions, and the urban and rural development of elderly education is unbalanced, and it is positively correlated with the level of digital development. At present, elderly education in some large and medium-sized cities in China has begun to take shape, with fixed school premises and digital teaching facilities and equipment, as well as the guarantee and support of school-running funds and full-time teachers. However, the elderly education in small cities and villages started late, digital teaching is in its infancy, the facilities and equipment and school-running places are relatively simple, and there is also a lack of relatively stable full-time teachers and school- 
running funds. The unbalanced development of education is relatively prominent, and further development is needed [4].

\subsection{There Is a Problem of One-Sided Ideological Understanding}

The essence of geriatric education is a kind of non-academic and non-formal education under the government-led model. It is an important part of China's national education system and lifelong education system with the elderly as the main educational service object. As China's education development focuses on basic education and higher education, senior education is in fact at the edge of education. For many years, senior universities in various places have mainly aimed at retirees with relatively high cultural levels. The limitation of this kind of education object has made senior universities not have a great influence and dissemination power in China. At present, the university for the elderly has just started, focusing on leisure and entertainment. In a certain sense, it can only be regarded as an "entertainment center" for the elderly. However, due to the rapid development of the times and the actual needs of the elderly, the society already has certain influence. Due to the misunderstanding, many people in the society still mistakenly regard the education for the elderly as bringing the elderly together for entertainment activities, which is equivalent to the art group of the civil society. Some government departments also treat it as a dispensable, thus directly or indirectly affecting the healthy development of the cause of education for the elderly.

\subsection{There Are Problems of Level Imbalance and Internal Resource Dispersion}

At present, the development of elderly education sponsored by different entities is in full swing. For example, the National Open University system, cultural system, education system, veteran cadre system, pension real estate, large pension institutions and other systems are all opening elderly education institutions. The main management departments of different senior education schools are different and have their own advantages, but the resources are relatively scattered, and it is difficult to form a joint force due to the lack of unified planning, overall planning and shared utilization. Some senior education does not have a clear competent department, and there is a problem of multiple management. Veteran Cadre University is headed by the Organization Department and sponsored by Veteran Cadre Bureau. Some universities for the elderly are under the Aging Commission, Civil Affairs Bureau and other departments, some are under the control of cultural and educational departments, and some are organized by social forces. Due to the lack of a clear competent authority, some elderly universities do not have legal permission to run schools, and there is a problem that the name is not justified. If the elderly education of different management subjects can realize the sharing of tangible resources such as school venues, teachers, high-quality courses, facilities and equipment, and intangible educational re- 
sources such as school-running concepts, educational ideas, educational brands, and school-running characteristics, it will greatly promote the elderly education. System construction and value pursuit, and promote the prosperity and development of senior education.

\subsection{There Is a Serious Shortage of Educational Venues}

Judging from the current situation of senior education in some areas of China, although three levels of senior education at district and county level, street level and community level have basically been built, most of them do not have independent sites and are basically shared with other units or departments. The number of times and the time should also be arranged according to the use of other units or departments. The activity venues, classrooms, and office spaces for elderly education are subject to greater restrictions, and necessary teaching equipment such as computers and pianos. It is also relatively scarce, resulting in the inability to offer many professional courses for the elderly, which cannot meet the learning needs of some elderly people. In the current stage of economic and social development, many universities for the elderly have actually become spiritual harbors for some elderly people to live in their later years, resulting in more and more elderly people who are reluctant to graduate from universities for the elderly. Some senior college students will continue to study as long as their physical conditions allow. "Only getting in but not getting in" is a major problem faced by older universities. If the old students do not leave, the new students will naturally not come in, which aggravates the shortage of educational resources to a certain extent.

\subsection{There Is a Shortage of School Funding and Full-Time Teachers}

Elderly education is a public welfare undertaking, and the fees charged to the elderly are very limited. Under normal circumstances, except for the elderly universities sponsored by government departments, some of which are funded through financial subsidies, other types of elderly universities have no financial allocation, and the financial pressure faced by running schools is increasing. , coupled with increasing expenditures, such as subsidies for teachers and administrators, make it increasingly difficult for older universities to operate. Because the elderly education is mostly unmanned and unstaffed, most teachers are hired from outside, part-time or from volunteer teams. The shortage of funds makes it impossible to establish a stable teaching team. Teachers are often changed in a semester or even an academic year, which is not conducive to curriculum construction and the accumulation and research of education and teaching experience. Many teachers who are engaged in community education work are also teachers of the corresponding disciplines. They do not get paid and are voluntary work, and it is difficult to improve their enthusiasm and ensure the quality of teaching [5]. 


\section{Suggestions for Improving the Work}

\subsection{Change of Thinking}

In order to establish a curriculum system with the goal of promoting the social participation of the elderly under the digital background, the curriculum setting should also be oriented to the needs of the learning subject. China's education work plan for the elderly clearly puts forward the goal of "six things" for the elderly to "support the elderly, learn from the elderly, enjoy the elderly, and do something for the elderly". The elderly in the new era have a certain level of professional knowledge, physical and mental health, and self-cultivation. Through re-learning and effective social participation, they will also become an indispensable human resource in an aging society. Realizing the active and extensive social participation of the elderly is not only the needs of the elderly themselves, but also the objective needs of social development in the context of aging. The construction of the senior education curriculum system must be guided by the goal and concept of promoting the comprehensive social participation of the elderly, to build a rich content, distinct level system, wide coverage, highly compatible with the social participation needs of the elderly, adapt to the needs of the times and conform to the core of socialism. Value-based elderly education curriculum system; it is necessary to provide the elderly with the knowledge and skills required for new roles, cultivate the ability of the elderly to participate in society, promote and promote the self-growth of the elderly, and meet the learning needs of the elderly at different levels; enrich the life of the elderly With spiritual connotation, it provides a platform for the elderly to participate in society, and improves the life satisfaction and sense of gain of the elderly.

\subsection{Strengthen Information Construction}

To establish an information technology support mechanism for elderly education under the background of big data, and to promote the precision of public services for elderly education, it should be based on information big data and based on specific urban and rural areas to build a smart elderly education information society that includes resources such as suppliers, demanders, and supervisors. system. The characteristics of precision, full sample, and personalization of big data are coupled with the precise supply of public services, which can promote the precise matching and seamless connection between the supply and demand of public services. Therefore, use the "Internet +" thinking to construct an information technology support mechanism for elderly education that integrates data collection, orderly storage, portrait analysis, supply consultation and effect evaluation, and use advanced Internet technology to enhance the matching degree between the learning needs of the elderly and the actual supply. It is the only way to improve the quality of the supply of public services for elderly education and promote the precision of public services for elderly education. To strengthen the information technology support mechanism for elderly education, first of all, we must fully absorb the achievements of information wisdom 
technology, build a public service information platform for elderly education, realize the seamless connection between the supply and demand sides, and ensure the rapid, timely and effective screening of the lifelong learning needs of the elderly group, capture, filter, categorize, process, deliver and feedback. The main contents include: First, promote the construction of an information platform for elderly education services, unblock the orderly communication channels between supply and demand, promote the interconnection of service data, improve the working mechanism of service resource allocation, periodically evaluate the quality of public service supply, and provide demand for all elderly learners. A shared platform for tracking, information transmission, and full-dimensional services. The second is to use big data mining technology and statistical analysis methods to accurately mine the massive data resources of public services for elderly education, and accurately predict the lifelong learning needs of the elderly based on the big data information of browsing traces of "online + offline" information terminals trend. The third is to develop massive online digital learning resources based on information technology, eliminate digital learning barriers for the elderly, integrate and optimize high-quality online courses based on APP terminals, provide mobile learning support services, and provide resource guarantees for the precision of public services for elderly education.

\subsection{Improve the Dynamic Detection Mechanism}

Establishing a dynamic elderly education quality monitoring mechanism under the digital background Quality monitoring is a key link and important content in the development of education modernization. The construction of a public service system for elderly education requires the guidance of a good quality monitoring mechanism. Therefore, the implementation of global quality monitoring is an effective way to improve the quality of public services for elderly education. To establish a dynamic quality monitoring mechanism for elderly education, the fundamental task is to construct and adapt a governance evaluation system to improve the development of the elderly education public service system, to form a strategy for promoting elderly education and a path for building a public service system based on the results of education quality monitoring. At the specific operational level, first of all, it is necessary to establish a fairness-oriented value orientation, clarify the policy orientation and operation scope of the quality monitoring of elderly education, and give full play to the tool function of quality monitoring in the provision of public services for elderly education, protection of rights and interests, and teaching evaluation. Secondly, it is necessary to clarify the subjects and objects of the quality monitoring of elderly education. The main body of monitoring should be the third party in the society, and encourage elderly learners, social third parties and stakeholders in the development of elderly education to participate in the implementation and implementation of elderly education quality monitoring use. Once again, it is necessary to pay attention to the particularity of elderly education, formulate scientific 
and appropriate quality monitoring standards and procedures, accelerate the research and development and production of quality assessment tools suitable for the development of elderly education, and establish and improve the quality monitoring and operation mechanism of elderly education.

\subsection{Improve the Evaluation Mechanism}

Carrying out a sound development evaluation mechanism that promotes construction and curriculum system construction through evaluation is an important means to promote the continuous improvement and development of the quality of the senior education curriculum system. The establishment of the evaluation mechanism must first establish perfect curriculum construction standards and norms; secondly, it is necessary to clarify the subject of curriculum evaluation implementation; thirdly, there must be a complete evaluation index system and reward and punishment mechanism. The formulation of standards and norms for the construction of senior education curriculum will help to ensure the quality of senior education curriculum, avoid the randomness of curriculum setting, and provide an effective dimension for assessment and evaluation after the implementation of curriculum teaching. The main body of the evaluation can be implemented by a third party or a regional senior education guidance center, and is responsible for establishing an evaluation index system, and implementing dynamic and regular evaluations of the curriculum system of senior education institutions to promote construction. In addition to examining core elements such as course design, course implementation, and course results, the evaluation index system also needs to pay attention to the evaluation opinions of the elderly students participating in the study.

\subsection{Strengthen Multiple Linkages}

Diversified supply is an inevitable choice for public services. It is necessary to give full play to the role of the government and non-governmental organizations in the supply of public services, improve supply efficiency, and form healthy competition. The core of the public education supply-side reform is to "expand the supply of high-quality educational resources, optimize the allocation of educational resources, provide more and better educational options, and resolve the long-standing and difficult problem of education". Diversified supply will change the singleness of the main body of social public service supply, give play to the joint role of multiple subjects such as government, market and society, advocate the establishment of a multi-supply mechanism for public services that integrates the government, the market and social organizations, and improve the quality of social public services, supply quality and efficiency. Establishing a public service supply mechanism for senior education led by the government, coordinated by departments, and participating in the society, to realize the diversification of the public service supply mechanism for senior education, and to meet the differentiated needs for lifelong learning is an important part of building a public service system for senior education and achieving precise supply link. First 
of all, we must establish a multi-supply linkage mechanism for elderly education. Focus on building partnerships based on the vision of common interests, reshaping the governance structure and interests of senior education, promoting the effective integration of cross-border and diverse subjects, and forming an ecological pattern that meets the individualized and customized needs of senior learners. Secondly, when establishing a multi-supply linkage mechanism, it is necessary to clarify the roles, responsibilities and boundaries of the main body of senior education responsibility, form a community of mutual trust and shared interests, and then build an effective, accurate and leading senior education supply system. On the basis of diversified supply, it is necessary to actively explore the market-oriented operation mechanism of elderly education, unite various social departments, sign work contracts through competitive bidding and other methods, and establish a virtuous circle of partnership. It is particularly important that under the background of changes in the main social contradictions, we should pay attention to the application of the concept of government procurement of services in the field of elderly education, establish standard and complete service procurement procedures, gradually standardize quality standards, establish a financial security system, and improve evaluation and evaluation. Risk prevention mechanism, and promote the path innovation of the diversified supply of public services for elderly education.

It can be seen that on the basis of changing ideas, by strengthening informatization construction, improving dynamic detection and evaluation mechanisms, and strengthening multiple linkages, it is possible to effectively speed up the construction of the elderly education system under the background of digital transformation and enrich its value pursuit. The problems of unbalance, lack of ideological awareness, scattered resources and shortage of teacher funds in the public services of elderly education should ensure that under the condition of limited public service resources, the level of precision in the supply of public services for elderly education can be improved to the greatest extent, and the realization of public education resources. The optimal allocation and efficient use of the system will promote the transformation and upgrading of education for the elderly, and achieve the goal of lifelong learning for the elderly.

\section{Fund Project}

Special project of lifelong education of Zhejiang open university in 2021 (No. ZSJY202110).

\section{Conflicts of Interest}

The author declares no conflicts of interest.

\section{References}

[1] Li, C.H. (2017) Re-Understanding of China's Elderly Education Theory under the New Situation. Contemporary Continuing Education, 8, 77-80.

[2] Notice of the General Office of the State Council on Printing and Distributing the 
Senior Education Development Plan (2016-2020). (Guobanfa [2016] No. 74). http://www.gov.cn/zhengce/content/2016-10/19/content 5121344.htm

[3] Peng, C.Y. and Zeng, Z. (2017) Research on the Relationship between Elderly Education and Social Participation of the Elderly and Its Countermeasures. Aging Science Research, 8, 35-42.

[4] Pan, D.Y. (2017) The Inspection and Construction of the Senior Education Curriculum System from the Perspective of the Demand Range Theory-Taking the Open University for the Elderly as an Example of the National Open University. Aging Science Research, 8, 35-42.

[5] Xie, Y. (2019) Research on the Practice of Running a School for the Elderly in Guangzhou TV University. Journal of Higher Continuing Education, 1, 68-73. 